\title{
Aisthesis. Revista Chilena de Investigaciones Estéticas. 50 años de trayectoria
}
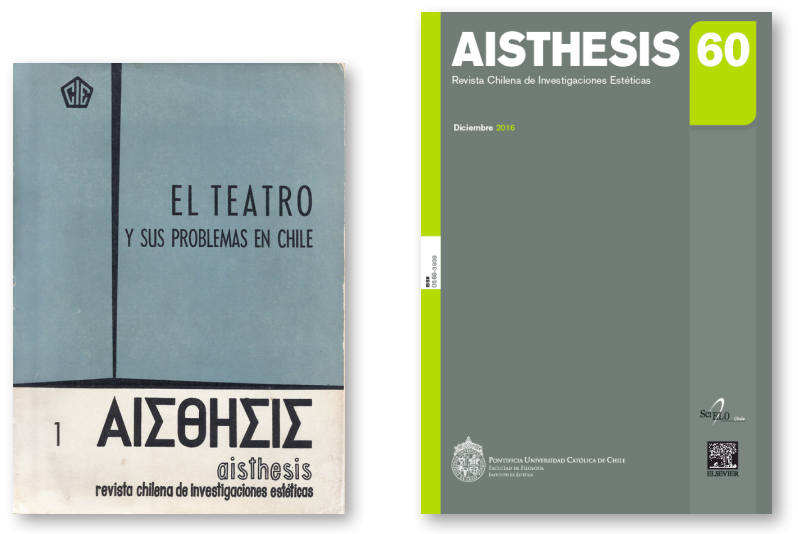

Revista Aisthesis cumple cincuenta años de trayectoria. Desde su aparición, en el año 1966, esta publicación se planteó como uno de sus objetivos fundamentales llevar a cabo una reflexión sobre la disciplina estética siempre en relación con las problemáticas de nuestra sociedad, pero buscando un vínculo también con América y otros países. Tal como expresa Enrique Gerias en la presentación de nuestro primer número: Años de inquietudes, meditaciones, estudios e investigaciones, han hecho posible la realidad del Centro de Investigaciones Estéticas, bajo la tuición de la Facultad de Filosofía y Ciencias de la Educación de la Universidad Católica de Chile, por feliz iniciática de su Decano, Dr. Raimundo Kupareo. Es así cómo esta Revista Chilena de Investigaciones Estéticas, no es una improvisación, sino el resultado del convencimiento de que es necesario dar a nuestra cultura una nueva visón de la riqueza artística acumulada desde los albores pre atacameños o pre araucanos hasta hoy. 
Consecuentemente, durante todos estos años nuestra política editorial ha estado enfocada en el desarrollo de diálogos interdisciplinarios a nivel nacional e internacional, con la filosofía como referente genealógico principal, pero teniendo en cuenta las relaciones con diversas áreas de las humanidades y las ciencias sociales. Así, hemos favorecido una articulación analítica y reflexiva con diferentes sistemas de sentido, tradiciones culturales y modalidades de expresión en épocas y lugares del pasado y del presente.

Cumpliendo nuestra voluntad de fomentar el desarrollo del conocimiento estético, y con el fin de dejar un testimonio de profesores e investigadores actuales del Instituto de Estética sobre los aportes que otros profesores hicieron en el pasado, publicamos este Dossier "50 años de trayectoria”. En él, planteamos un recorrido por las diversas temáticas contenidas en nuestra revista, profundizando en problemáticas tocantes a las expresiones visuales, sonoras y orales como manifestaciones que comprenden diversas instancias de producción simbólica. Esperamos que estas reflexiones constituyan un aporte específico al intercambio académico con áreas de estudio como la historia, la teoría del arte, la crítica de arte y la crítica cultural, bajo los fundamentos filosóficos, religiosos y antropológicos de la experiencia estética, en sus dimensiones educacionales y sociológicas. Tal aporte, reiteramos, hace especial énfasis en las culturas latinoamericanas y del territorio chileno, desde el campo del registro analítico de la obra de arte al espacio social de la cultura, en vinculación con sus diversas instancias de producción simbólica.

Los objetivos planteados en la aparición de nuestro primer número se han cumplido en la publicación ininterrumpida de sesenta números de la revista. En 1966, se manifestaba que: "hemos iniciado un diálogo que durará como duran los pueblos; un diálogo con la creación artística, porque en este último rincón del orbe, está todo por hacer, por re-visar y re-a actualizar". Hoy, una vez más, tomamos los desafíos de revisar y reactualizar nuestro conocimientos a través de la producción de este Dossier que busca dar cuenta de nuestro trabajo como académicos e investigadores del Instituto de Estética, partícipes de una larga tradición.

Margarita Alvarado Pérez

Directora

Revista Aisthesis 